\title{
1 Plasticity of cold hardiness in the eastern spruce budworm, Choristoneura fumiferana
}

2 SKYE BUTTERSON ${ }^{1}$, AMANDA D. ROE ${ }^{2}$ and KATIE E. MARSHALL ${ }^{1, *}$

$3{ }^{1}$ Department of Zoology, University of British Columbia, Vancouver, BC V6T 1Z4,

$4 \quad$ Canada; kmarshall@ zoology.ubc.ca

$5{ }^{2}$ Great Lakes Forestry Centre, Natural Resources Canada, Sault Ste. Marie, ON P6A 2E5,

6 Canada; amanda.roe@ canada.ca

7 * Correspondence: kmarshall@ zoology.ubc.ca

8

9

10

11 Abstract

12

High latitude insect populations must cope with extreme conditions, particularly cold temperatures. Insects use a variety of cold hardiness mechanisms to withstand this temperature stress, and these can drive geographic distributions through overwintering mortality. The degree of cold hardiness can be altered by two evolved responses: phenotypic plasticity and local adaptation. Phenotypic plasticity can occur within or between generations (transgenerational plasticity; TGP), and local adaptation can evolve through directional selection in response to regional climatic differences. We used the eastern spruce budworm, Choristoneura fumiferana (Lepidoptera: Tortricidae) as a model to explore the role that variable winter temperatures play in inducing two aspects of plasticity in cold hardiness: TGP and local adaptation in phenotypic plasticity. This species is one of the most destructive boreal forest pests in North America, therefore accurately predicting overwintering survival is essential for effective management. While we found no evidence of TGP in cold hardiness, there was a long-term fitness cost to larvae that experienced repeated cold exposures. We also found evidence of local adaptation in both seasonal and short-term plasticity of cold hardiness. These findings provide evidence for the 
bioRxiv preprint doi: https://doi.org/10.1101/2021.04.02.438273; this version posted April 4, 2021. The copyright holder for this preprint (which

was not certified by peer review) is the author/funder, who has granted bioRxiv a license to display the preprint in perpetuity. It is made available under aCC-BY-ND 4.0 International license.

27 importance of phenotypic plasticity and local adaptation when modelling species 28 distributions.

29 Key words. Winter ecology; phenotypic plasticity; transgenerational plasticity; local

30 adaptation; Lepidoptera; Choristoneura fumiferana

31

32 


\section{Introduction}

Cold hardiness during overwintering is an important determinant of temperate insect survival. Body fluids of small ectotherms are especially at risk of freezing in winter environments due to their relatively low thermal inertia (Lee, 2010). Freezing is deadly for most species; ice crystal formation causes mechanical damage to cells and cellular dehydration results in an accumulation of solutes and altered biochemical gradients (Lee, 2010). Among cold hardy insects, cold hardiness strategies can be divided into freeze tolerance and freeze avoidance (Sinclair, 1999). While freeze tolerant insects can survive internal ice formation, freeze avoidant insects survive low temperatures by depressing their supercooling point (SCP; the temperature at which their internal fluid freeze. The SCP is depressed through a number of processes such as: the dehydration of body water content (Han and Bauce, 1998), expression of low-molecular weight cryoprotectants like glycerol (Churchill and Storey, 1989), and production of ice binding proteins (IBPs; Duman, 2015).

The ability to respond to cold stress can vary by region, and these differences can arise through a combination of basal genetic adaptations and phenotypic plasticity (Sinclair et al., 2012). Adaptive differences arise as environmental conditions select for regionally adapted genotypes, leading to localized genetic differentiation. Phenotypic plasticity - the capacity of a single genotype to produce multiple environmentally-induced phenotypes - is an induced response to thermal variability (Pigliucci, 2001). These basal and plastic responses to cold stress may coevolve (Calosi et al., 2008), or manifest as a trade-off where populations with high basal cold hardiness have low phenotypic plasticity in variable thermal conditions (Kellermann et al., 2018). Disentangling these processes requires exploring cold hardiness among populations within a common-garden framework or using reciprocal transplant experiments (Overgaard et al., 2010).

Plastic responses to temperature can occur over multiple timescales. In the short term, an individual can develop resistance to stressful cold temperatures by hardening, which occurs 
rapidly after short exposures to sub-lethal conditions and is usually reversible (Kelty, 2007).

Rapid cold hardening $(\mathrm{RCH})$ is a form of hardening that occurs within minutes to hours after a cold exposure (Lee and Denlinger, 2010). Acclimation, on the other hand, is a more gradual adjustment to cold temperatures that occurs over a period of days to months (Lee, 2010). Both hardening and acclimation can lead to increased cold hardiness and may share biochemical mechanisms such as cryoprotectants and membrane modifications to achieve this phenotype, but there is evidence that they involve non-overlapping mechanisms (Rajamohan and Sinclair, 2009). Furthermore, repeated cold exposure can cause significant up-regulation of cryoprotectant concentrations beyond the effects of a single exposure (reviewed in Marshall and Sinclair, 2012). Responses to cold can depend on developmental stage and even age, with stage-specific tolerance shifting over time (Bowler \& Terblanche 2008). For example, cold hardiness in Drosophila melanogaster varies across life stages (Jensen et al., 2008), with eggs having greater cold tolerance than other life stages. Plastic, stage-specific variation in temperature tolerance can contribute to mortality and population dynamics, which may be critical in determining the geographic distribution of a species (Bowler and Terblanche, 2008).

Plastic responses to cold stress can also extend beyond a single generation and impact future offspring through transgenerational plasticity. Maternal effects are the most frequently studied form of transgenerational plasticity (TGP; reviewed in Mousseau and Fox, 1998), but can also include paternal, grandparental, and potentially earlier generational effects. Transgenerational responses to temperature occur in many insect species (Woestmann and Saastamoinen, 2016). For example, diapause in the offspring of the cabbage beetle, Colaphellus bowringi, is modulated by the temperatures and photoperiods experienced by their parents. Moreover, the expression of diapause itself in the parental generation predicts the absence of diapause in the subsequent generation (He et al., 2018). Collectively, thermal conditions experienced by a population of insects can alter their immediate phenotypic 
response and have cascading impacts on the response and fitness of subsequent generations, making it critical to examine the phenotypic responses to cold stress over a range of timescales.

The ability to respond to temperature variability and the degree of that plastic response can, in itself, show local adaptation (Calosi et al., 2008; Kawecki and Ebert, 2004), resulting in variable expression among populations (Chown, 2001; Sinclair et al., 2012). For example, Daphnia magna, a widely distributed zooplankton, exhibits both local adaptation and adaptive plasticity in temperature tolerance (Yampolsky et al., 2013), with individuals from warmer sites expressing higher heat tolerance than those from cooler locations. The populations also showed variable degrees of acclimation to warmer temperatures that further increased heat tolerance, suggesting adaptive plasticity. This form of plasticity may be particularly important in species with large distributions, as climatic conditions can vary substantially along latitudinal or altitudinal gradients, providing a mechanism for local populations to respond to regional temperature conditions.

The eastern spruce budworm (Choristoneura fumiferana Clemens, 1865) is a destructive forest pest found throughout the northern boreal forest (Fig. 1), whose distribution spans $\sim 24$ degrees of latitude and over 80 degrees of longitude. This distribution represents a large winter temperature gradient, where populations in the southern range will experience a much milder winter climate than those in the northern latitudes. Spruce budworm survives winter as second instar larvae in silken overwintering structures (called hibernacula) and undergoes a six to eight month dormancy (Han and Bauce, 1993; Marshall and Roe, n.d.; Régnière, 1990). Ice formation is lethal to C. fumiferana, so the SCP represents a physiological and fitness limit for this freeze avoidant species. Second instar larvae are the primary overwintering stage and can depress their SCP to $\sim-35^{\circ} \mathrm{C}$ (Han and Bauce, 1995a) by accumulating 0.8 M glycerol (Han and Bauce, 1995b), expressing IBPs (Qin et al., 2007; Tyshenko et al., 1997), and decreasing their internal water content (Bauce E and Han, 2001; 
111 Han and Bauce, 1998; Marshall and Roe, n.d.). While capable of surviving very brief

112 exposures to temperatures near their $\mathrm{SCP}$, exposure to $-15^{\circ} \mathrm{C}$ for more than ten days can

113 result in mortality (Han and Bauce, 1995a). There is also evidence that fluctuating

114 temperatures can further induce significant plasticity in cold tolerance on short time scales

115 (i.e. days, Marshall and Sinclair, 2015), even in seasonally-acclimated individuals. $C$.

116 fumiferana larvae overwintered outside have significantly lower SCPs than larvae

117 overwintering in laboratory conditions (Han and Bauce, 1993), suggesting that fluctuating

118 conditions may be a critical cue for inducing a greater response to cold stress than expressed

119 under constant temperatures.

120 The vast majority of cold tolerance work for $C$. fumiferana has been based on a

121 laboratory strain maintained at the Insect Production and Quarantine Laboratories (IPQL,

122 Natural Resources Canada, Great Lakes Forestry Centre, Sault Ste. Marie, Ontario, Canada).

123 The IPQL laboratory strain was established from multiple populations in Ontario and has

124 been in culture for over 60 years (Roe et al., 2017). Genetic drift and historical population

125 bottlenecks, as well as potential laboratory adaptation to constant temperatures, could limit

126 the general applicability this strain to characterize cold stress responses of wild populations.

127 The ability of $C$. fumiferana to withstand low temperature stress, particularly in northern

128 latitudes, is crucial to understanding their overwintering capacity, and by extension, their

129 geographic distribution (Gray, 2008; Régnière, 2009). Currently, winter conditions at the

130 northern edges of their range exceed these published limits, which suggests that cold

131 hardiness capacities in the eastern spruce budworm may be significantly under-reported and

132 vary throughout their range. Hence, we need to explore the intraspecific variation in basal

133 and plastic cold tolerance to determine the overwintering capacity of the spruce budworm.

134 Spruce budworm larvae do not feed after hatching, but prepare for diapause immediately

135 following eclosion. This means that the energy reserves needed to survive winter and initiate

136 spring development are entirely dependent on parental investment (Sanders, 1991). 
137 Therefore, conditions or stress experienced by the parental generation could affect the cold

138 tolerance of their offspring via TGP. For example, acclimating Calliphora vicina to lower

139 fall temperatures decreases the SCP of their offspring by $3{ }^{\circ} \mathrm{C}$ (Coleman et al., 2014). In $C$.

140 fumiferana, previous work has found transgenerational fitness effects on offspring fitness,

141 driven by parents' nutritional status as sixth-instars (Carisey and Bauce, 2002). It is,

142 however, unclear whether TGP influences the overwintering capacity of $C$. fumiferana or

143 contributes to its adaptive plasticity in cold tolerance.

144 The basic mechanisms of cold hardiness in C. fumiferana are well understood, however,

145 we know little about the role plasticity and local adaptation plays in the survival of this

146 widespread species. Using new laboratory strains of $C$. fumiferana (Perrault et al., 2021), we

147 tested two hypotheses: 1) that spruce budworm populations have local adaptation in the

148 plasticity of cold hardiness on either seasonal or short-term timescales, and 2) that this

149 plasticity induces TGP in cold hardiness. We found that while fluctuating temperatures

150 induced plasticity in cold hardiness, there was no evidence that this plasticity was

151 transgenerational. However, strains of $C$. fumiferana from higher latitudes exhibited greater

152 basal cold hardiness and significantly more plasticity than those from lower latitudes.

\section{Materials and methods}

154

155

156

157

158

159

160

161

\section{Experimental animals}

We performed all experiments on second-instar diapausing Choristoneura fumiferana caterpillars obtained from IPQL. Transgenerational plasticity experiments were conducted on the "IPQL" strain (Roe et al., 2017) established in 1961 (Glfc:IPQL:Cfum). Local adaptation in plasticity experiments were conducted on colonies established from wild populations as reported in Perrault et al. (2021; Fig. 1). Regional colonies used in this study originated from Campbellton, New Brunswick (Glfc:IPQL:CfumBNB01, "New Brunswick" 
$\left.16358^{\circ} 50^{\prime} 71^{\prime \prime} \mathrm{N} 117^{\circ} 14^{\prime} 03^{\prime \prime} \mathrm{W}\right)$, Inuvik, Northwest Territories (Glfc:IPQL:CfumINT01,

164 "Inuvik" $\left.68^{\circ} 21^{\prime} 56.2^{\prime \prime} \mathrm{N} 133^{\circ} 42^{\prime} 04.9^{\prime} \mathrm{W}\right)$. The Alberta and Inuvik populations correspond to

165 the "Central" genomic cluster identified in Lumley et al. (2020), with the remaining

166 populations contained within the "Eastern" cluster. These regional strains were kept in

167 culture for one (late diapause measures) or two generations before use (all other measures).

168 We received dormant larvae in newly-spun hibernacula embedded in gauze from IPQL via

169 overnight shipping on ice packs to the University of British Columbia. Once received, larvae

170 were placed into an incubator (MIR-154, Sanyo, Bensenville, USA) held at $2{ }^{\circ} \mathrm{C}$ in constant

171 darkness.

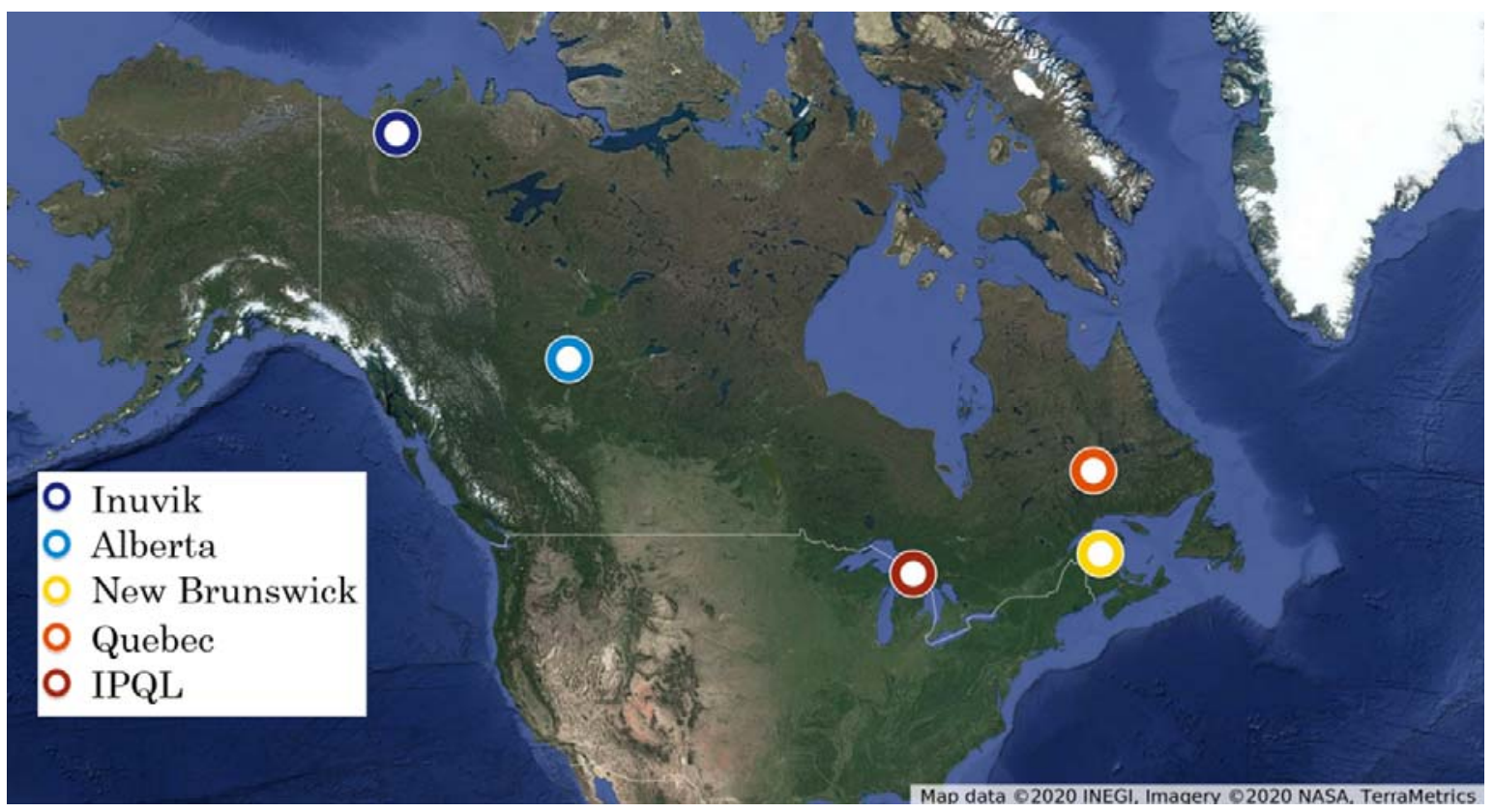

174 Fig. 1. Map of population sampling localities.

We assessed local adaptive plasticity in four colonies of eastern spruce budworm

177 recently derived from wild populations (Inuvik, Alberta, Quebec, New Brunswick). We

178 tested two aspects of locally adaptive plasticity in cold hardiness during diapause: 1) in 
constant dormancy temperatures, and 2) following variable cold exposure regimes. The first was tested by measuring larvae either six or twelve weeks into diapause (held at $2{ }^{\circ} \mathrm{C}$ under constant darkness), constituting the "early" and "late" diapause groups, respectively. To test the effect of variable temperatures, early diapause groups were further separated into "basal" or "inducible". Individuals in the "inducible" treatment group were held at $2{ }^{\circ} \mathrm{C}$ for six weeks, then exposed to five repeated cold events of $-15{ }^{\circ} \mathrm{C}$ for 12 hours with a return to $2{ }^{\circ} \mathrm{C}$ for 12 hours (ramp rate of $0.05{ }^{\circ} \mathrm{C} /$ minute). No caterpillars from the New Brunswick population were exposed to the inducible treatment due to limited sample numbers.

\section{Experimental design: Transgenerational plasticity}

We explored whether parental cold stress would generate a transgenerational response in C. fumiferana larval cold tolerance. First, we exposed the parental population to different temperature regimes, then measured SCP, biochemical properties, and lower lethal temperature (LLT). We exposed 980 diapausing IPQL caterpillars to four cold temperature regimes: control, single 1 , single 2 , and repeated. "Control" insects were kept at $2^{\circ} \mathrm{C}$ for six weeks. "Single 1 " insects were kept at $2{ }^{\circ} \mathrm{C}$ for six weeks, then exposed to $-10{ }^{\circ} \mathrm{C}$ for 12 hours (including a ramp rate of $0.05^{\circ} \mathrm{C} /$ minute) and measurements were made after 24 hours at 2 ${ }^{\circ} \mathrm{C}$. "Single 2 " insects were kept at $2{ }^{\circ} \mathrm{C}$ for six weeks, then exposed to $-10{ }^{\circ} \mathrm{C}$ for 12 hours (including a ramp rate of $0.05{ }^{\circ} \mathrm{C} /$ minute) and measurements were made after 152 hours $(\sim 6$ days and 8 hours) at $2{ }^{\circ} \mathrm{C}$ to account for differences in the time since first cold exposure between "single 1" and "repeated". "Repeated" insects were kept at $2{ }^{\circ} \mathrm{C}$ for six weeks, then exposed to five repeated cold events of $-10{ }^{\circ} \mathrm{C}$ for 12 hours with a return to $2{ }^{\circ} \mathrm{C}$ for 12 hours (ramp rate of $0.05{ }^{\circ} \mathrm{C} /$ minute). We provide detailed descriptions of these cold exposure techniques below (see Cold exposures). All temperature treatments were conducted in total darkness. Following temperature exposures, we haphazardly selected 20 individual larvae for SCP measurements, five sets of 10 larvae for biochemical assays, and five sets of 20 larvae 
204 for LLT measurements. We also retained a subset of individuals (10 sets of 10 larvae) from

205 the parental treatment groups to generate $F_{1}$ progeny and repeated the cold tolerance

206 measurements on the $\mathrm{F}_{1}$ progeny (i.e. SCP and biochemical properties).

207

208

209

210

211

212

213

214

215

216

217

218

\section{Cold exposures}

To conduct cold exposures, we placed microcentrifuge tubes containing larvae into a milled aluminum block (Sinclair et al., 2015) connected to a programmable refrigerated circulating bath (Lauda Proline RP 3530, Wurzburg, Germany) containing 50:50 ethylene glycol:water. Ten 36 AWG Type T (copper-constantan) thermocouples (Omega Engineering Inc., Laval, Canada) were placed in the block to monitor temperature. These thermocouples were interfaced with PicoTech TC-08 thermocouple interfaces connected to a computer running PicoLog software (Pico Technology, Cambridge, U.K.) taking temperature samples in the block every 0.5 seconds. The bath was set to cycle between 2 and $-15^{\circ} \mathrm{C}\left(\mathrm{OR}-10{ }^{\circ} \mathrm{C}\right.$ for TGP exposures) for 12 hours each including ramping rates between these temperatures of $0.05{ }^{\circ} \mathrm{C} / \mathrm{min}$ for five full cycles. Larvae were returned to the incubator in diapausing conditions for 24 hours to recover after the exposure.

\section{Measures of cold hardiness}

\section{Supercooling point (SCP)}

SCPs were measured as in (Strachan et al., 2011). Briefly, we removed larvae from their hibernacula and stored them in $1.8 \mathrm{~mL}$ microcentrifuge tubes until SCP measurements. We attached 20 individual caterpillars to 36 AWG Type T copper-constantan thermocouples with a thin layer of vacuum grease. We threaded these thermocouples through the pierced top of the $1.8 \mathrm{~mL}$ microcentrifuge tubes and held in place with adhesive putty.

We floated each tube on a 60:40 methanol: water solution in a programmable refrigerated circulating bath (Lauda ECO RE 1050, Wurzburg, Germany). The refrigerated 
228 circulating bath was cooled from 2 to $-38^{\circ} \mathrm{C}$ at a rate of $0.09^{\circ} \mathrm{C} /$ minute. SCP was recorded as

229 the temperature immediately prior to the onset of the exotherm (Lee, 2010; Sinclair et al., 230 2015). Late diapausing Inuvik caterpillars could not be reliably frozen using the

231 abovementioned method. In this case, SCPs were estimated by placing computer-interfaced

232 thermocouples attached to individual caterpillars in microcentrifuge tubes in Styrofoam

233 freezer boxes and then into a $-80{ }^{\circ} \mathrm{C}$ freezer. The cooling rate for this exposure can only be

234 estimated in this case as $9{ }^{\circ} \mathrm{C} /$ minute.

\section{Biochemical assays for energetics and metabolites}

236 We removed larvae from their hibernacula and stored them as in SCP treatment. We then 237 homogenized groups of 10 caterpillars with approximately $900.5 \mathrm{~mm}$ Zirconium oxide 238 beads (Next Advance Inc., Averill Park, USA) in a Bullet Blender (Storm 24, Next Advance 239 Inc., Averill Park, USA) for two minutes at the highest speed. After initial blending, we 240 added $50 \mu \mathrm{L} 0.05 \%$ Tween 20 and repeated blending. An additional $250 \mu \mathrm{L} 0.05 \%$ Tween 20 241 was added and the sample was mixed using a vortexer (Vortex-Genie 2, Scientific Industries 242 Inc., Bohemia, USA). Following mixing, we centrifuged each sample (Allegra 64R, 243 Beckman Coulter Canada Inc., Mississauga, Canada) for 10 min at 15,000 $\times g$. We removed 244 two aliquots of the supernatant and stored the samples at $-80{ }^{\circ} \mathrm{C}$ for later assays.

245 Glycerol, glucose, glycogen and protein content was measured using spectrophotometric 246 assays following (Marshall and Sinclair, 2015) using glycerol, glucose and Type II glycogen 247 from oyster and bovine serum albumin as standards, respectively. Briefly, glycerol was 248 measured using a Free Glycerol kit (MAK117, Sigma-Aldrich Canada Co., Oakville, 249 Canada). Glucose was measured using a hexokinase-based Glucose assay kit (GAHK20, 250 Sigma-Aldrich Canada Co.). Glycogen content was measured using the same kit following 251 an $8 \mathrm{~h}$ amyloglucosidase (A9228, Sigma-Aldrich Canada Co.) digestion in a dark drawer at 252 room temperature. Soluble protein was measured using a Bicinchronicinc acid kit (BCA1, 
253 Sigma-Aldrich Canada Co.). Absorbance of each reaction was measured in a

254 spectrophotometer (Spectra Max M2, Molecular Devices, San Jose, USA) and calculated 255 concentrations are reported in $\mu \mathrm{mol} /$ individual.

256 Additional measures for TGP experiment: Lower lethal temperature (LLT) and rearing $F_{1}$

257 progeny

258 To estimate LLT, five groups of 20 caterpillars within their hibernacula from each 259 treatment group were exposed to either $-15,-20,-25,-30$, or $-35^{\circ} \mathrm{C}$, as described in (Sinclair 260 et al., 2015). Groups of larvae were exposed to their corresponding temperature treatment for 2614 hours, by putting the pierced $1.8 \mathrm{~mL}$ microcentrifuge tubes into a milled aluminum block as 262 described for the cold exposure treatments. After exposure, they were transferred to Petri 263 dishes. Mortality was assessed under the microscope (MEB126, Leica, Wetzlar, Germany) 264 by checking if caterpillars were dehydrated, out of their hibernaculum or immobile, at five 265 different time points throughout development (one week after exposure, at the end of 266 diapause (20 weeks from the onset of diapause), at thinning (10 days after ending diapause, 267 between instar 3 and 4) and at pupation, following the rearing protocols explained below. 268 Dead caterpillars were removed at each time point. The temperature at which $50 \%$ of the 269 group survived $\left(\mathrm{LT}_{50}\right)$ was calculated at each time point by assessing mortality to determine 270 both change in $\mathrm{LT}_{50}$ after different cold exposures (treatments) and change in $\mathrm{LT}_{50}$ over 271 development (time).

272 After the cold exposures, the mating group was returned to diapausing conditions $\left(2{ }^{\circ} \mathrm{C}\right.$ 273 in constant darkness) for a total of 20 diapausing weeks (including the initial six weeks 274 pretreatment and treatment time). Following this, they were put into feeding/developing 275 conditions $\left(24^{\circ} \mathrm{C}\right.$, with a 16:8 light: dark cycle) as detailed in (Marshall and Sinclair, 2015). 276 Briefly, groups of 10 caterpillars were put onto diet cups with artificial diet (McMorran, 277 1965) purchased through Insect Production and Quarantine Services 
278 (https://www.nrcan.gc.ca/science-data/research-centres-labs/forestry-research-centres/great-

279 lakes-forestry-centre/insect-production-services/13467). Insects were placed on fresh diet

280 once a week to avoid the accumulation of frass, microbes and mold. Ten days later, one

281 caterpillar was put into each cup (thinning). At pupation, we sterilized pupae with a $10 \%$

282 bleach solution under a fume hood, rinsed with deionized water and left to dry on paper

283 towels. They were then sexed under a microscope and the first 40 individuals were weighed

284 on a microbalance (CP 124 S, Sartorius, Göttingen, Germany). Males and females were

285 moved to separate ventilated plastic containers to emerge. These emergence chambers were

286 checked daily for emerged adult moths. The first 20 male and female moths (total of 40

287 moths) that emerged were put into 20 L clear plastic bags with three sets of five $5 \times 5 \mathrm{~cm}$

288 strips of waxed paper stapled together. A 50:50 female and male ratio was maintained in each

289 bag. Each treatment's mating chamber was sprayed with deionized water before and after

290 take-down. The three mating chambers were kept in environmental chambers $\left(23 \pm 3^{\circ} \mathrm{C}, 55 \pm\right.$

291 10\% RH, 16L:8D) in the Faculty of Forestry at the University of British Columbia. Mating

292 chambers were set-up for a week, after which moths died and egg masses were collected.

293 Emergence pans for egg masses were set-up using $30 \times 25 \times 5 \mathrm{~cm}$ baking trays lined with

294 gauze and sealed with Parafilm and electrical tape to avoid larval escape. Once second-instar

295 caterpillars began spinning their hibernacula, the emergence pans were opened to count the

296 number of larvae that had emerged and spun their hibernacula. The gauze was then removed,

297 wrapped it with Parafilm, and put it in an incubator held at $2{ }^{\circ} \mathrm{C}$ in constant darkness.

298 After six weeks into diapause, all measures of cold hardiness were repeated with $\mathrm{F}_{1}$ 299 second-instar larvae.

Statistics

$301 \quad$ All statistical tests and data plots were conducted in RStudio (version 1.1.463, 2018). To 302 test for transgenerational plasticity, a Type II ANOVA model was fitted for each cold 
303 hardiness measure using the aov function in the car package (Fox and Weisberg, 2019) with

304 generation and treatment as predictors. To test for local adaptation in cold hardiness, the 305 same model was fitted with population, diapause stage and treatment as predictors. For

306 biochemical assays, we used protein concentration as a covariate in the model. LLTs were

307 calculated at each assessed time point using a generalized linear model with binomial error 308 distribution and the dose.p function with p set to 0.5 from the MASS package (Venables and 309 Ripley, 2003). Alpha was set to 0.05 for all tests. p-values less than 0.01 are reported as such.

310 All significant interactions were further investigated using TukeyHSD posthoc tests.

\section{Results}

312 Local adaptation in phenotypic plasticity of cold hardiness

313 Spruce budworm populations showed significant differences in cold hardiness, 314 particularly as larvae progressed in diapause. Late diapause individuals from the Inuvik 315 population had a significantly lower SCP compared to other populations and times tested 316 (population: $\mathrm{F}_{(2,119)}=4.87, \mathrm{p}<0.001$; time: $\mathrm{F}_{(1,119)}=16.06, \mathrm{p}<0.001$; population $\times$ time: $317 \mathrm{~F}_{(2,119)}=5.43, \mathrm{p}<0.01$; Fig. 2A). Population had a significant effect on basal glycerol content

318 (population: $\mathrm{F}_{(2,29)}=13.85, \mathrm{p}<0.001$; Fig. $2 \mathrm{~B}$ ). In this case, larvae from Inuvik significantly 319 increased their glycerol by the late diapause time point, whereas larvae from New Brunswick 320 significantly decreased glycerol content during the same timeframe. Glycogen 321 concentrations were significantly affected by time (time: $F_{(1,29)}=11.27, p<0.01$; Fig. $2 C$ ). 322 Population and time in diapause also had a significant effect on basal total carbohydrate 323 concentrations (population: $F_{(2,29)}=3.196$, $p=0.020$; time: $F_{(1,29)}=15.96$, $p<0.001$ ), with New 324 Brunswick larvae in early diapause having lower total carbohydrate content than the early 325 diapause larvae from Inuvik and Quebec (Fig. A2). 


\section{A)}

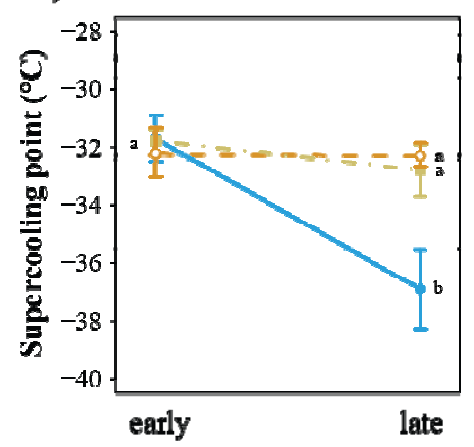

327

328

329

330

331

332

333

334

335

336

338 protein mass as a covariate. Fig. A3).

\section{B)}

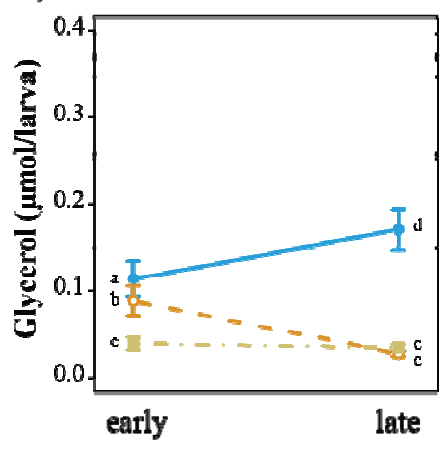

Time in diapause
C)

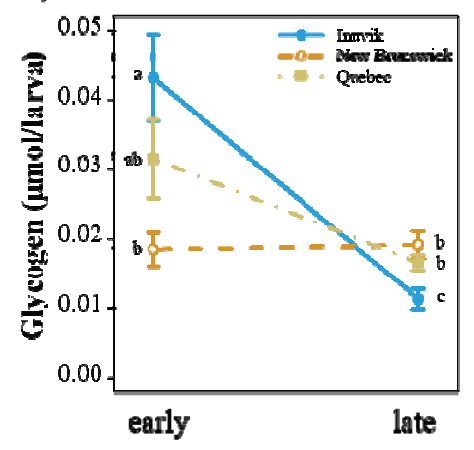

Fig. 2. Testing for local adaptation in seasonal plasticity without pretreatment. A) Supercooling point $\left.\left(\mathrm{SCP} ;{ }^{\circ} \mathrm{C}\right), \mathrm{B}\right)$ glycerol per larva $(\mu \mathrm{mol})$ and $\left.\mathrm{C}\right)$ glycogen per larva $(\mu \mathrm{mol})$ of second-instar Choristoneura fumiferana across different populations measured at either early (6 weeks) or late (12 weeks) into diapause. Glycogen is measured in glucose units. Points with the same letter are not statistically significantly different in an ANCOVA with

We exposed larvae to repeated cold events to examine the differences between basal cold hardiness and an inducible plastic response. We found a significant interaction between population and repeated cold exposures on SCP (population: $F_{(3,169)}=10.32, p<0.001$; treatment: $F_{(1,169)}=15.80, p<0.001$; population $\times$ treatment: $F_{(3,169)}=3.654, p=0.014$; Fig. $\left.3 A\right)$. A significant effect of population and treatment was found on glycerol concentrations (population: $\mathrm{F}_{(3,39)}=36.47, \mathrm{p}<0.001$; treatment: $\mathrm{F}_{(1,39)}=31.31, \mathrm{p}<0.001$; population $\times$ treatment: $F_{(3,39)}=7.24, p<0.001$; Fig. 3B). Alberta and Inuvik decreased their SCP after exposure, whereas Quebec and the IPQL remained the same. For glycogen; there was no effect of population or treatment (population: $\mathrm{F}_{(3,39)}=0.123$, $\mathrm{p}=0.12$; treatment: $\mathrm{F}_{(1,39)}=0.534$, $\mathrm{p}=0.47$; Fig. $3 \mathrm{C}$ ). The same was true for total carbohydrate, there was no significant effect of population or treatment (population: $\mathrm{F}_{(3,39)}=2.765$, $\mathrm{p}=0.058$; treatment: $\mathrm{F}_{(1,39)}=0.88, \mathrm{p}=0.35$; 
A)

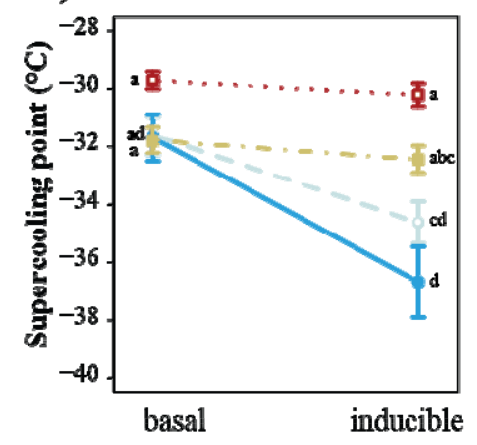

348

349

350

351

352

353

354

355

356

357

358

359

360

361 with protein mass as a covariate.

Fig. 4).
B)

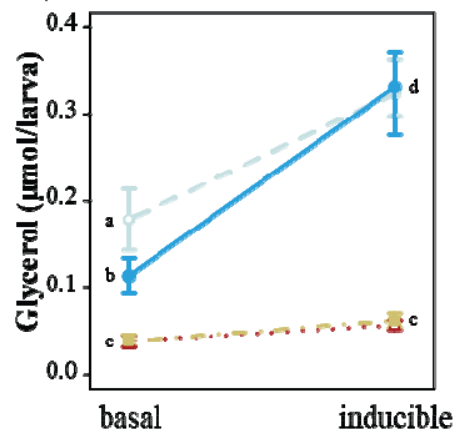

Treatment
C)

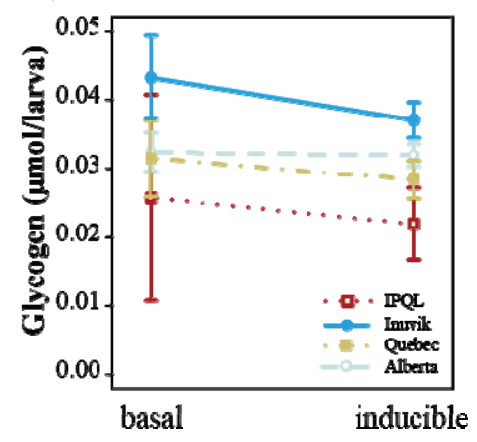

Fig. 3. Testing for local adaptation in short-term response to temperature variation. A) Supercooling point $\left.\left(\mathrm{SCP} ;{ }^{\circ} \mathrm{C}\right), \mathrm{B}\right)$ glycerol per larva $(\mu \mathrm{mol})$ and $\left.\mathrm{C}\right)$ glycogen per larva $(\mu \mathrm{mol})$ of second-instar Choristoneura fumiferana before ("basal") and after ("induced") five exposures to $-15{ }^{\circ} \mathrm{C}$. Different letters indicate statistically significant comparisons $(\mathrm{p} \leq \alpha)$. All exposures were conducted on early diapause larvae. Glycogen is measured in glucose units. Points with the same letter are not statistically significantly different in an ANCOVA

\section{Transgenerational plasticity of cold hardiness}

In the IPQL strain, repeated cold exposures did not significantly change SCP of either generation, although $\mathrm{SCP}$ was higher in the $\mathrm{F}_{1}$ generation (generation: $\mathrm{F}_{(1,139)}=63.77, \mathrm{p}<0.01$; 

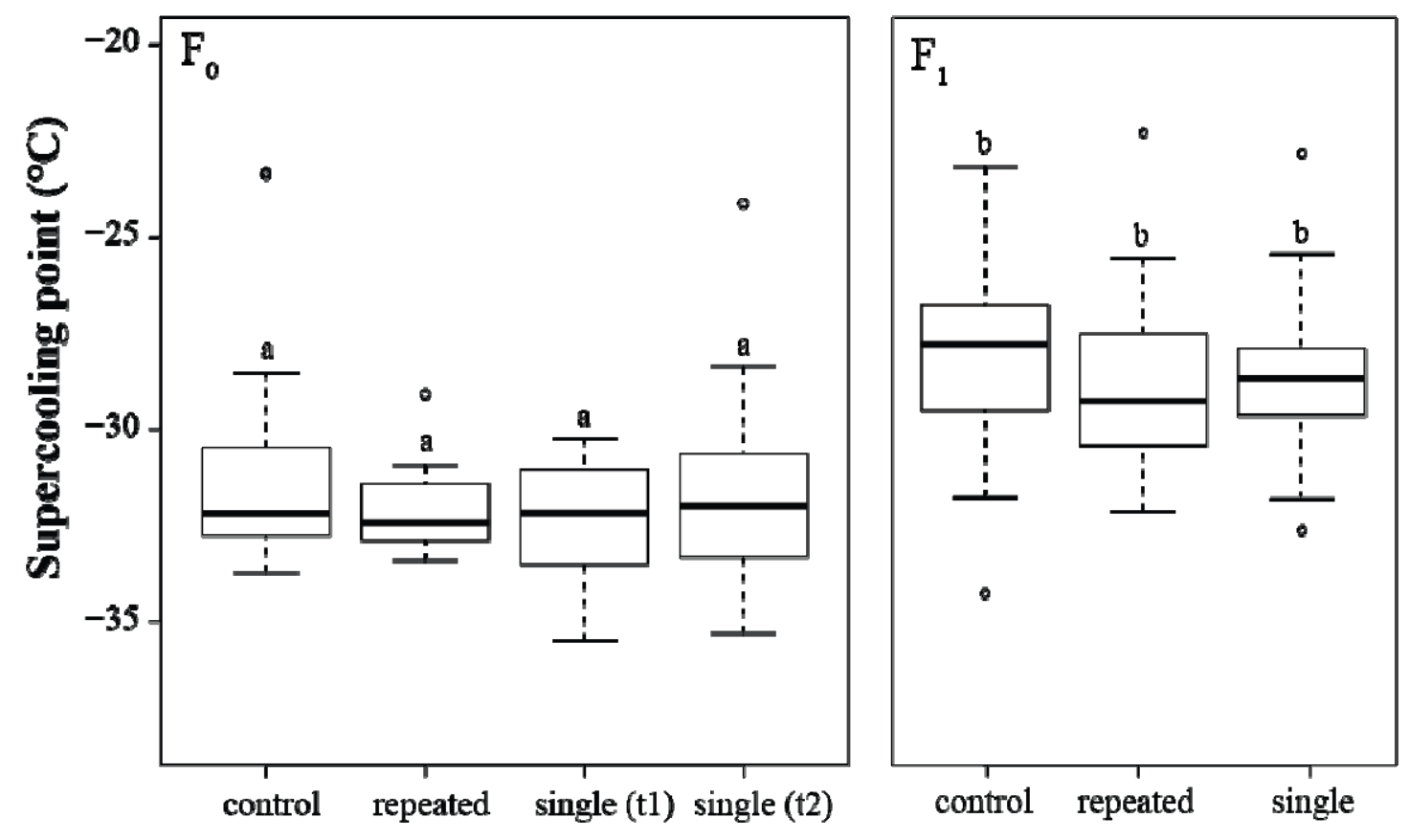

\section{Treatment}

363 Fig. 4. Supercooling points (SCP) $\left({ }^{\circ} \mathrm{C}\right)$ as a result of cold exposures and generation in second 364 instar IPQL Choristoneura fumiferana larvae. Bold line inside box shows median, lower and upper box boundaries show 25th and 75th percentile, respectively, lower and upper error lines show 10th and 90th percentile, respectively. Treatment groups are Single T1 (larvae exposed to a single cold exposure of $-10{ }^{\circ} \mathrm{C}$ for $12 \mathrm{hrs}$ and assessed 24 hours after), Single T2 (larvae exposed to a single cold exposure of $-10{ }^{\circ} \mathrm{C}$ for $12 \mathrm{hrs}$ and assessed at the same time as the repeated group) and Repeated (larvae exposed to five cold exposures of $-10{ }^{\circ} \mathrm{C}$ for 12 hrs and assessed 24 hours after). Different letters indicate statistically significantly different comparisons $(\mathrm{p} \leq \alpha)$.

We calculated $\mathrm{LT}_{50}$ for each treatment group at four time points following exposure to

374 five temperatures. We assessed mortality one week after exposure, at the end of diapause (20

375 weeks from the onset of diapause), thinning (between instar 3 and 4) and following pupation

376 (Fig.s A4-7). The effect of cold exposure on $\mathrm{LT}_{50}$ depended on the time of assessment and

377 treatment (time point: $\mathrm{F}_{(3,15)}=58.63$, $\mathrm{p}<0.001$; treatment: $\mathrm{F}_{(3,15)}=4.18, \mathrm{p}=0.047$ ). Individuals

378 exposed to a single cold event (but sampled at the same time as the repeated group, Single 2)

379 had a higher $\mathrm{LT}_{50}$ at every time-point assessed, except at the end of diapause, compared to

380 other treatments (Fig.. 5). Additionally, $\mathrm{LT}_{50}$ increased with time as mortality effects accrued 
381 through development. Larvae that experienced repeated cold exposures had the lowest $\mathrm{LT}_{50}$

382 at every time point.

383

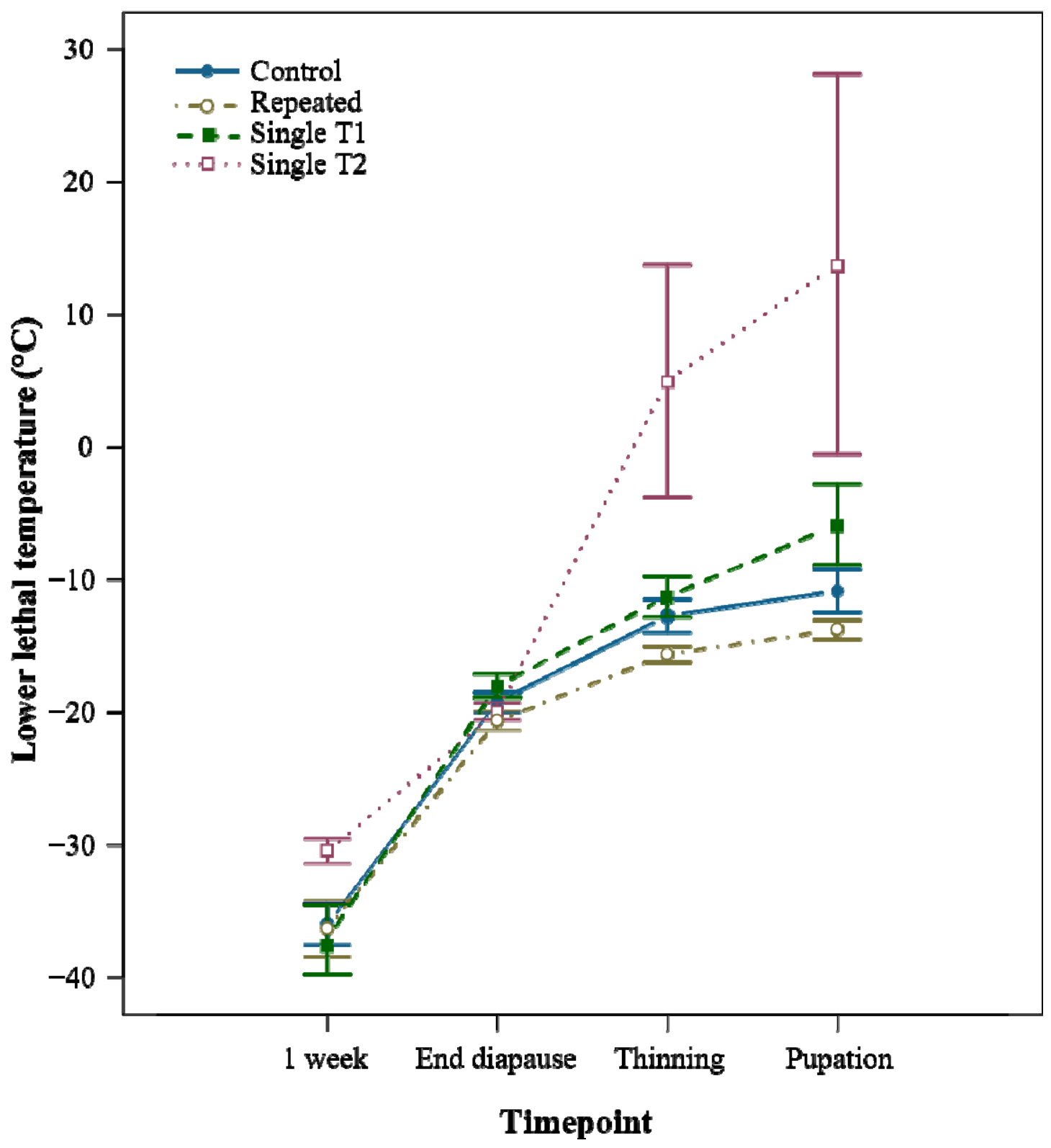

385 Fig. 5. Lower lethal temperature (LLT), displayed as $\mathrm{LT}_{50}$, of $\mathrm{F}_{0}$ second-instar IPQL (Choristoneura fumiferana) larvae after different cold exposures shown in color. Error bars show standard error of the $\mathrm{LT}_{50}$ estimate. Treatment groups are Single 1 (larvae exposed to a single cold exposure of $-10{ }^{\circ} \mathrm{C}$ for $12 \mathrm{hrs}$ and assessed 24 hours after), Single 2 (larvae exposed to a single cold exposure of $-10{ }^{\circ} \mathrm{C}$ for $12 \mathrm{hrs}$ and assessed at the same time as the repeated group) and Repeated (larvae exposed to five cold exposures of $-10{ }^{\circ} \mathrm{C}$ for $12 \mathrm{hrs}$ and assessed 24 hours after). 
393 Cold exposure and generation had a significant effect on energy reserves and metabolites

394 measured in our biochemical assays. Cold exposure caused no significant differences in

395 glycerol content (treatment: $\mathrm{F}_{(3,34)}=1.039, \mathrm{p}=0.39$ ). This can be attributed to the large

396 variance $(\mathrm{sd}=0.08)$ compared to the other treatment groups in $\mathrm{F}_{0}(\mathrm{sd}<0.01$; Fig. $6 \mathrm{~A})$.

397 Glycogen content significantly differed among treatments (treatment: $F_{(3,34)}=7.60, p<0.001$ ),

398 with control and single 1 being significantly lower than single 2 and repeatedly cold exposed

399 larvae (Fig. 6B). There was no significant interaction between treatment and protein mass

400 (treatment $\times$ total protein: $\mathrm{F}_{(3,34)}=2.03 \mathrm{p}=0.13$ ). Glycogen concentrations differed with

401 protein mass (total protein: $\mathrm{F}_{(1,34)}=43.81, \mathrm{p}<0.001$ ). Total carbohydrate significantly

402 differed among treatments (treatment: $\left.\mathrm{F}_{(3,34)}=5.42, \mathrm{p}<0.01\right)$. Post-hoc tests indicated larvae in

403 treatments single 2 and repeated had significantly higher total carbohydrate content than

404 larvae in the control and single 1 treatments (Fig. A1). 

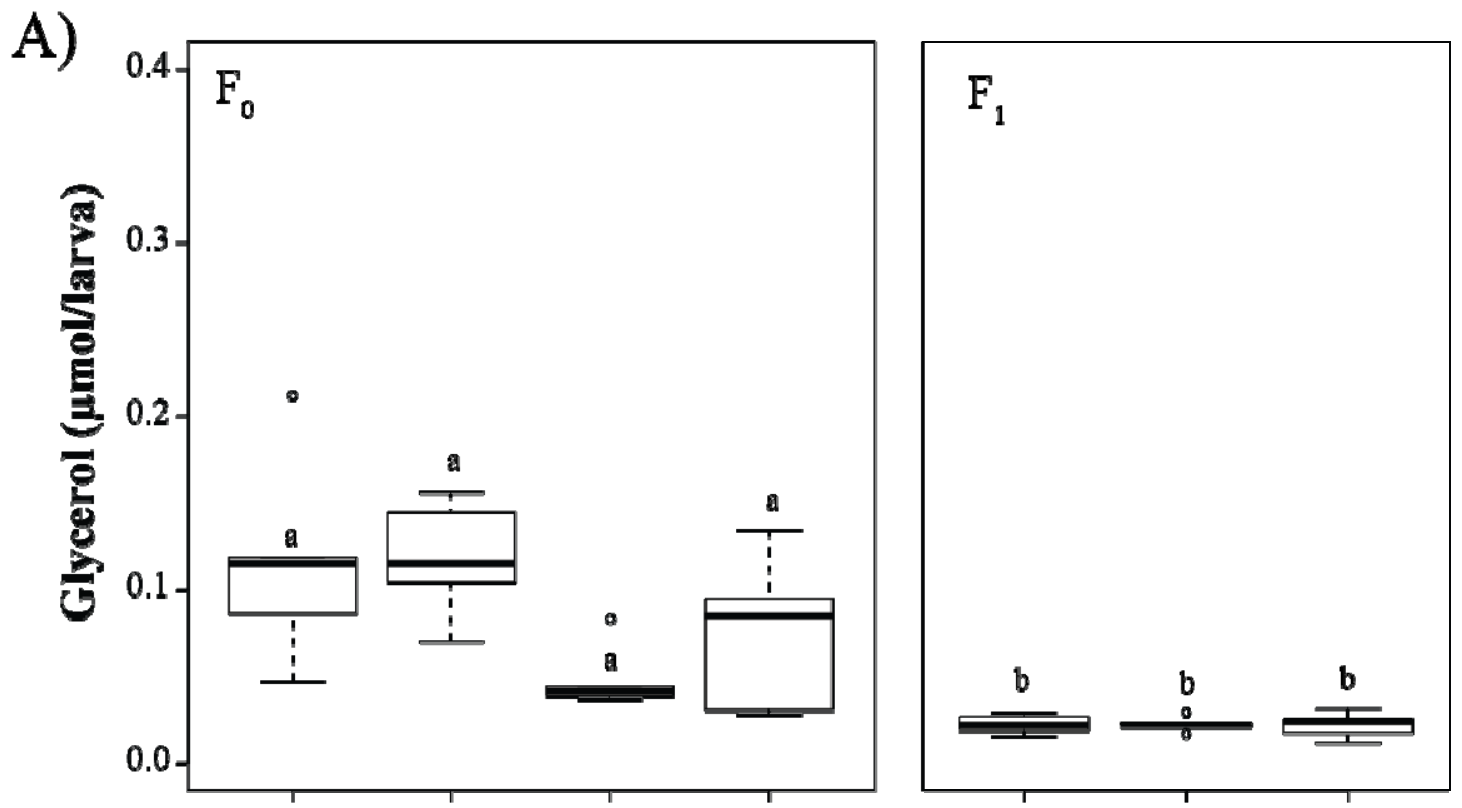

B)
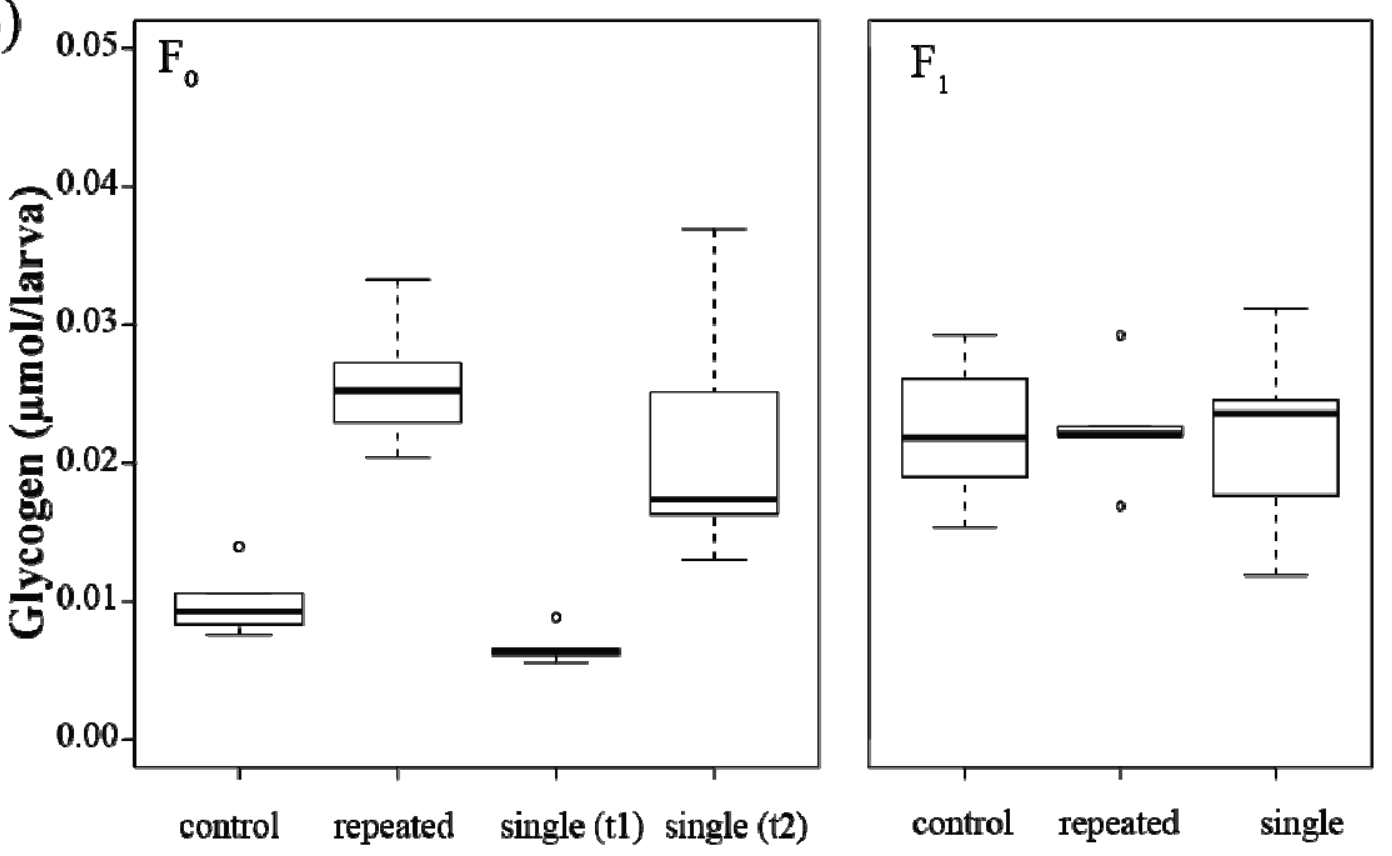

407 Fig. 6. A) Glycerol per larva ( $\mu \mathrm{mol})$ and B) Glycogen per larva ( $\mu \mathrm{mol})$ across the different 408 treatments and two generations in second-instar IPQL Choristoneura fumiferana larvae. 409 Refer to Fig. 2 caption for explanation of boxplot display and treatment groups. Letters 410 indicate statistically significant comparisons $(\mathrm{p} \leq \alpha)$. Glycogen is measured in glucose units. 411 Points with the same letter are not statistically significantly different in an ANCOVA with 412 protein mass as a covariate. 
415 Geographic differences in cold tolerance can arise from genetic variation, phenotypic 416 plasticity, or their interaction (reviewed in Chevin et al., 2010). Here, we explored the 417 relationship between local adaptation and plasticity in overwintering capacity using $C$. 418 fumiferana, an ecologically and economically important forest insect pest. We found 419 regional differences in both seasonal and short-term plasticity of cold hardiness in $C$. 420 fumiferana, suggesting local adaptation to winter climates. Regional differences in 421 short-term plasticity were greater than differences in basal cold hardiness in early diapause 422 larvae, emphasizing the importance of inducible responses in high latitude populations. We 423 found no evidence for TGP despite a significant reduction in $\mathrm{F}_{0}$ fitness following repeated 424 cold exposures. Our results highlight the importance of regional differences in cold tolerance, 425 particularly the capacity for northern populations to respond to variable winter conditions. 426 We suggest that future studies consider regional differences in spruce budworm populations 427 and include seasonal and short-term plasticity when quantifying overwintering capacity.

428 Seasonal plasticity in insect cold tolerance is well described (Bale, 2002). Generally, our 429 populations reduced their SCPs and shifted metabolite concentration as diapause progressed. 430 Similar results were previously found in the IPQL laboratory strain, with cold tolerance and 431 metabolites changing over the dormancy period (Marshall and Sinclair, 2015). However, our 432 results indicated that these patterns of seasonal plasticity varied among populations. While 433 our populations did not differ in their basal SCP in early diapause (Fig. 2A, 3A), late diapause 434 larvae from high latitudes had significantly lower SCPs compared to lower latitude 435 populations (Fig. 2A). These larvae also had significantly higher glycerol content compared 436 to lower latitude populations and their increased glycerol content corresponded to reductions 437 in SCP. Our results suggest that $C$. fumiferana has significant local adaptation to seasonal 438 winter conditions.

439 High latitude populations experience significantly longer and colder winters than 440 populations at lower latitudes (Marshall et al., 2020). Recent studies have shown that local 
441 adaptation in the degree of seasonal cold tolerance occurs across a range of native and

442 invasive insects (Batz et al., 2020; Marshall et al., 2020; Williams et al., 2015). As expected,

443 spruce budworm populations from high latitudes (e.g. Inuvik, Northwest Territories and

444 High Level, Alberta) had greater overwintering capacity than eastern populations at lower

445 latitudes. The basal SCP for late diapause Inuvik insects is lower than results published for $C$.

446 fumiferana larvae from the IPQL lab colony under identical experimental and rearing

447 conditions (Han and Bauce, 1995a; Marshall and Sinclair, 2015). In fact, we actually

448 encountered methodological challenges measuring SCPs for these northern individuals. We

449 were unable to freeze late-diapause Inuvik larvae using a refrigerated circulating bath, a

450 method successful for other populations in our study. Therefore, we had to use a $-80{ }^{\circ} \mathrm{C}$

451 freezer to reach temperatures low enough to initiate freezing in these larvae. An important

452 difference in these two methods is that the cooling rate in the freezer was faster $\left(9^{\circ} \mathrm{C} / \mathrm{min}\right)$

453 than the programmable bath $\left(0.09^{\circ} \mathrm{C} / \mathrm{min}\right)$. There is evidence that cooling rates can influence

454 absolute thermal limits (Terblanche et al., 2007), so the faster cooling rate of the freezer

455 could have artificially depressed the SCP of the Inuvik insects. However, given that we

456 switched to this method because the Inuvik population would not freeze under conditions

457 used for other populations, and they consistently had lower SCP measurements than southern

458 populations in other experiments (i.e. following repeated cold exposures, Fig. 6A), we are

459 confident that the lower SCP in late diapause larvae is accurate.

460 Short-term plasticity allows organisms to respond rapidly to variable environmental 461 conditions through inducible responses. We verified that fluctuating temperatures induced 462 greater cold tolerance in C. fumiferana than constant temperatures alone (Marshall and 463 Sinclair, 2015), and then demonstrated that high latitude populations expressed a 464 significantly greater magnitude of plasticity than lower latitude populations (Fig 3). 465 Short-term plasticity allows insects to respond to variable temperatures in a short temporal 466 timeframe (reviewed in Marshall and Sinclair, 2012). The ability to rapidly respond to 
467 temperature shifts would be advantageous in northern climates where winter conditions are

468 significantly more variable than southern latitudes (Marshall et al., 2020). Both seasonal and 469 short-term plasticity combine to provide high latitude populations greater overwintering 470 capacity than their southern counterparts.

471 Theoretical models often pit local adaptation against phenotypic plasticity (e.g. Sultan 472 and Spencer, 2002), however these results indicate that phenotypic plasticity itself may be 473 under local adaptation, particularly in insect overwintering. Spruce budworm populations 474 in our study represented two distinct genetic backgrounds: Central and Eastern subclusters 475 (Lumley et al., 2020). Our high latitude populations belong to the Central cluster, while New 476 Brunswick and Quebec belong within the Eastern cluster. In fact, the IPQL population was 477 founded from populations in eastern Canada, giving it the same genetic background as our 478 other eastern populations. Even though the IPQL strain has been maintained in colony since 479 the 1960s (Roe et al., 2017) and does not experience cold temperature stress, it was 480 functionally equivalent to Eastern populations. Genomic differences between these central 481 and eastern $C$. fumiferana populations are defined by a block of single nucleotide 482 polymorphisms located on a single linkage group (LG4, Lumley et al., 2020). The authors 483 noted that one of these variant loci was associated with glycerol-3-phosphate dehydrogenase 484 (GPDH). GPDH is known to be involved in the glycerol synthesis pathway in other insects 485 (Park and Kim, 2013), which is a key cryoprotectant in C. fumiferana (Han and Bauce, 486 1995b; Marshall and Sinclair, 2015) and insects in general (Lee, 2010). Larvae from the 487 Central cluster produced elevated glycerol concentrations, so this genomic variation could be 488 linked to the functional differences we observed. Further exploration of these genomic 489 variants in the context of glycerol production will be critical to resolving the underlying 490 mechanisms driving local adaptation in C. fumiferana.

491 Transgenerational plasticity (TGP) allows insects to survive in variable climates by 492 inducing increased tolerance to temperature stress in future generations. First, however, we 
493

494

495

496

497

498

499

500

501

502

503

504

505

506

507

508

509

510

511

512

513

514

515

516

517

518

needed to demonstrate that repeated cold exposures triggered a cold stress response in the $\mathrm{F}_{0}$ generation. While we found that SCP did not change among the $\mathrm{F}_{0}$ treatment groups, we noted a decrease in $\mathrm{LT}_{50}$ in caterpillars that received repeated cold exposures. As such, we took this as a response to temperature stress and the insects altered their cold hardiness. Additionally, we found that treatment groups differed in mortality over time, suggesting that cold temperatures caused injury that manifested at later developmental stages. Although we did not observe a significant increase in glycerol content as a result of cold exposure, it is possible that unmeasured cold hardiness mechanisms (e.g. heat shock proteins or antifreeze proteins) could be responsible for this increased cold hardiness. Our results align with previous work (Han and Bauce, 1995a) and although tolerance to acute cold temperatures is very high as measured by SCP, the resultant chilling injury resulting from temperatures above the SCP is still significant. These results suggest that we induced a significant cold stress response in our $\mathrm{F}_{0}$ generation and established the selective environment for a transgenerational response.

Despite inducing a cold stress response in our $\mathrm{F}_{0}$ generation, we did not detect evidence of TGP in cold tolerance in our $\mathrm{F}_{1}$ generation. This lack of TGP after repeated cold exposures could be due to post-diapause feeding which masked the effect of stress-induced TGP (Tauber and Tauber, 1986). We did, however, find that $\mathrm{F}_{0}$ parents who experienced repeated cold exposures experienced a substantial decrease in fecundity $(>50 \%)$, similar to results observed in the vinegar fly Drosophila melanogaster (Marshall and Sinclair, 2010) even when food was not limiting. Variable, stressful environments can impact many fitness traits, including growth, body size, energy stores, and development, ultimately leading to reduced fecundity (Buckley et al., 2021). High latitude or high elevation populations are exposed to highly variable temperature environments, which can lead to a combination of short-term mortality and long-term reproductive effects that impact overall population demographics (Buckley et al., 2021). Mechanistically, this lowered reproductive output 
could be due to an inability to replenish depleted energetic reserves or long-term damage. We did not detect differences in pupal weights, which suggests that individuals were likely able to replenish themselves during the post-stress feeding stage, and instead it is more likely that chronic damage was incurred that was not reflected in overall weight. Larval exposure to heat stress in D. melanogaster can cause developmental defects in eclosing adults which is ameliorated in strains with higher HSP70 copy number (and therefore expression), suggesting that unrepaired protein damage may persist through metamorphosis (Roberts and Feder, 1999). It is, therefore, not inconceivable that the same is true for cold stress in overwintering larvae (reviewed in King and MacRae, 2015), and would be worthwhile exploring in greater detail.

TGP can only be adaptive when environmental conditions are predictable between parent and offspring lifecycles. Larval $C$. fumiferana are short-distance dispersers; they are capable of dispersing between a few trees by "ballooning" on silken threads or walking to different parts of the tree crown (Johns and Eveleigh, 2013; Nealis, 2016). By comparison, adult moths disperse much larger distances, sometimes hundreds of kilometers (Sturtevant et al., 2013). Therefore, the probability of shared environmental conditions between generations is low, and TGP of cold hardiness in second-instars is not favored by selection. It is also possible that TGP occurs in other winter-related traits rather than in absolute cold hardiness or supplied energetic reserves. For example, Harvey (1961) found that some fourth-instar $C$. fumiferana undergo a second diapause. The expression of a second diapause may be a plastic response to environmental variability. If so, TGP could be observed in diapause expression among larval instars since it is likely that environmental predictability between instars is higher than between generations. The lack of TGP in our measures of cold hardiness could also be due to using a lab-selected strain. The IPQL strain has been in culture since 1961 and has not been augmented with wild material for the past 20 years (Roe et al., 2017). Therefore, the relaxed selection of cold hardiness under lab conditions could have 
545 resulted in a very different response compared to wild populations. Wild populations may

546 differ in this respect, and would be an important area for further study.

\section{Conclusions}

548 The eastern spruce budworm has a broad geographic range in North America, so 549 populations are exposed to very different temperature regimes across this range. It was 550 hypothesized that populations would exhibit local adaptation in seasonal as well as 551 short-term plasticity. Two populations tested, Alberta and Inuvik, showed a similar degree of 552 short-term plasticity, which we attribute to the geographic connectivity between the 553 populations. Generally, there were no differences in basal cold hardiness among the 554 populations we tested, however seasonal and repeated cold exposures revealed evidence for 555 local adaptation of plasticity in the populations. These results have direct implications for the 556 predicted population growth, range shifts, and current species distribution modelling for the 557 species. The IPQL lab strain, which forms the basis of our current understanding of cold 558 hardiness in the species, shows comparatively low plasticity. Therefore, shifting thermal 559 regimes in local environments due to climate change, leading to increased temperature 560 extremes that select for plasticity, will result in highly variable regional responses among 561 spruce budworm populations.

562 Winter and higher latitudes have experienced the most change in temperature under new 563 climate conditions (Marshall et al., 2020; Zhang et al., 2019), exposing populations to novel 564 thermal environments across their ranges. Understanding the regional responses of 565 populations across a species' range is critical for predicting future changes in population 566 growth and species distribution throughout the boreal forest. Absence of evidence for cold 567 hardiness TGP in the IPQL strain suggests that TGP does not need to be incorporated into 568 population growth or species range models in C. fumiferana. However, it does provide 
570 fitness trade-offs in overwintering insects exist. Further work should focus on untangling the

571 potential mechanisms of these trade-offs, and future modelling should include fitness effects

572 of repeated cold exposures.

573 Local adaptation and phenotypic plasticity can and should be included in species

574 distribution models for C. fumiferana. Bush et al. (2016) highlights the use of hybrid species

575 distribution models, which uses trait mean, variability, heritability and the plasticity of a trait

576 to determine range shifts, therefore incorporating both plasticity and evolution. Diamond

577 (2018) tested this AdaptR model and found that range loss for 17 species of Drosophila

578 decreased by $33 \%$ in 2105 when incorporating these additional traits. For $C$. fumiferana,

579 accurately modelling species distributions with these spatio-temporal adaptive models could

580 prove useful for species management in future climates.

\section{Acknowledgments}

582 The authors with to express gratitude to everyone who helped with the creation of this

583 manuscript. Thanks to Ashlyn Wardlaw, Kerry Perrault, and the Insect Production and

584 Quarantine Laboratories (Natural Resources Canada) for rearing and maintaining the spruce

585 budworm colonies central to this project.

586

\section{Funding Sources}

588 This work was supported by NSERC Discovery Grant (RGPIN-2019-04239) to K.E.M.

590 Author Contributions: Conceptualization, S.B., A.D.R. and K.E.M.; laboratory

591 experiments, S. B.; analyses, S.B. and K.E.M.; manuscript preparation, S.B., K.E.M.

592 Data availability statement Data and code is available on the Open Science Framework.

\section{References}


595

596

597

598

599

600

601

602

603

604

605

606

607

608

609

610

611

612

613

614

615

616

617

618

619

620

621

622

623

624

625

626

627

628

629

630

631

632

633

Bale, J.S., 2002. Insects and low temperatures: from molecular biology to distributions and abundance. Philos. Trans. R. Soc. Lond. B. Biol. Sci. 357, 849-862. https://doi.org/10.1098/rstb.2002.1074

Batz, Z.A., Clemento, A.J., Fritzenwanker, J., Ring, T.J., Garza, J.C., Armbruster, P.A., 2020. Rapid adaptive evolution of the diapause program during range expansion of an invasive mosquito. Evolution (N. Y). 74, 1451-1465. https://doi.org/10.1111/evo.14029

Bauce E, Han, E., 2001. Desiccation resistance in pre-diapause, diapause and post-diapause larvae of Choristoneura fumiferana (Lepidoptera: Tortricidae). Bull. Entomol. Res. 91, 321-326. https://doi.org/10.1079/BER2001119

Bowler, K., Terblanche, J.S., 2008. Insect thermal tolerance: What is the role of ontogeny, ageing and senescence? Biol. Rev. 83, 339-355. https://doi.org/10.1111/j.1469-185X.2008.00046.x

Buckley, L.B., Schoville, S.D., Williams, C.M., 2021. Shifts in the relative fitness contributions of fecundity and survival in variable and changing environments. J. Exp. Biol. 224, jeb228031. https://doi.org/10.1242/jeb.228031

Bush, A., Mokany, K., Catullo, R., Hoffmann, A., Kellermann, V., Sgrò, C., McEvey, S., Ferrier, S., 2016. Incorporating evolutionary adaptation in species distribution modelling reduces projected vulnerability to climate change. Ecol. Lett. 19, 1468-1478. https://doi.org/10.1111/ele.12696

Calosi, P., Bilton, D.T., Spicer, J.I., 2008. Thermal tolerance, acclimatory capacity and vulnerability to global climate change. Biol. Lett. 4, 99-102. https://doi.org/10.1098/rsbl.2007.0408

Carisey, N., Bauce, E., 2002. Does nutrition-related stress carry over to spruce budworm, Choristoneura fumiferana (Lepidoptera: Tortricidae) progeny? Bull. Entomol. Res. 92, 101-108. https://doi.org/10.1079/BER2001148

Chevin, L.M., Lande, R., Mace, G.M., 2010. Adaptation, plasticity, and extinction in a changing environment: Towards a predictive theory. PLoS Biol. 8, e1000357. https://doi.org/10.1371/journal.pbio.1000357

Chown, S.L., 2001. Physiological variation in insects: hierarchical levels and implications. J. Insect Physiol. 47, 649-660. https://doi.org/10.1016/S0022-1910(00)00163-3

Churchill, T.A., Storey, K.B., 1989. Metabolic correlates to glycerol biosynthesis in a freeze-avoiding insect, Epiblema scudderiana. J. Comp. Physiol. B 159, 461-472. https://doi.org/10.1007/BF00692418

Coleman, P.C., Bale, J.S., Hayward, S.A.L., 2014. Cross-generation plasticity in cold hardiness is associated with diapause, but not the non-diapause developmental pathway, in the blow fly Calliphora vicina. J. Exp. Biol. 217, 1454-1461. https://doi.org/10.1242/jeb.098053

Diamond, S.E., 2018. Contemporary climate-driven range shifts: Putting evolution back on 
the table. Funct. Ecol. 32, 1652-1665. https://doi.org/10.1111/1365-2435.13095

635

636

637

638

639

640

641

642

643

644

645

646

647

648

649

650

651

652

653

654

655

656

657

658

659

660

661

662

663

664

665

666

667

668

669

670

671

672

Duman, J.G., 2015. Animal ice-binding (antifreeze) proteins and glycolipids: an overview with emphasis on physiological function. J. Exp. Biol. 218, 1846-55. https://doi.org/10.1242/jeb.116905

Fox, J., Weisberg, S., 2019. An R Companion to Applied Regression:, Third. ed, Robust Regression in R. SAGE Publications, Thousand Oaks, California.

Gray, D.R., 2008. The relationship between climate and outbreak characteristics of the spruce budworm in eastern Canada. Clim. Change 87, 361-383. https://doi.org/10.1007/s10584-007-9317-5

Han, E.-N., Bauce, E., 1993. Physiological changes and cold hardiness of spruce budworm larvae, Choristoneura fumiferana (Clem.), during pre-diapause and diapause development under laboratory conditions. Can. Entomol. 125, 1043-1053. https://doi.org/doi:10.4039/Ent1251077-6

Han, E.N., Bauce, E., 1995a. Non-Freeze Survival of Spruce Budworm Larvae, Choristoneura fumiferana, at Subzero Temperatures during Diapause. Entomol. Exp. Appl. 75, 67-74.

Han, E.N., Bauce, E., 1995b. Glycerol synthesis by diapausing larvae in response to the timing of low temperature exposure, and implications for overwintering survival of the spruce budworm, Choristoneura fumiferana. J. Insect Physiol. 41, 981-985. https://doi.org/10.1016/0022-1910(95)00049-Z

Han, E.R.N., Bauce, E., 1998. Timing of diapause initiation, metabolic changes and overwintering survival of the spruce budworm, Choristoneura fumiferana. Ecol. Entomol. 23, 160-167. https://doi.org/10.1046/j.1365-2311.1998.00111.x

Harvey, G.T., 1961. Second Diapause in Spruce Budworm from Eastern Canada. Can. Entomol. 93, 594-602. https://doi.org/10.4039/Ent93594-7

He, H.M., Xiao, H.J., Xue, F.S., 2018. Parental effect of diapause in relation to photoperiod and temperature in the cabbage beetle, Colaphellus bowringi (Coleoptera: Chrysomelidae). Bull. Entomol. Res. 108, 773-780. https://doi.org/10.1017/S0007485318000019

Johns, R.C., Eveleigh, E.S., 2013. Ontogeny and Stand Condition Influence the Dispersal Behavior of a Defoliating Specialist Caterpillar. Environ. Entomol. 42, 1329-1337. https://doi.org/10.1603/EN13083

Kawecki, T.J., Ebert, D., 2004. Conceptual issues in local adaptation. Ecol. Lett. 7, 1225-1241. https://doi.org/10.1111/j.1461-0248.2004.00684.x

Kellermann, V., Hoffmann, A.A., Overgaard, J., Loeschcke, V., Sgrò, C.M., 2018. Plasticity for desiccation tolerance across Drosophila species is affected by phylogeny and climate in complex ways. Proc. R. Soc. B Biol. Sci. 285. https://doi.org/10.1098/rspb.2018.0048

Kelty, J., 2007. Rapid cold-hardening of Drosophila melanogaster in a field setting. Physiol. 
673

674

675

676

677

678

679

680

681

682

683

684

685

686

687

688

689

690

691

692

693

694

695

696

697

698

699

700

701

702

703

704

705

706

707

708

709

710

Entomol. 32, 343-350. https://doi.org/10.1111/j.1365-3032.2007.00584.x

King, A.M., MacRae, T.H., 2015. Insect Heat Shock Proteins During Stress and Diapause. Annu. Rev. Entomol. 60, 59-75. https://doi.org/10.1146/annurev-ento-011613-162107

Lee, R.E., Denlinger, D.L., 2010. Rapid cold-hardening: Ecological significance and underpinning mechanisms. Low Temp. Biol. Insects 35-58.

Lee, Richard E., 2010. A primer on insect cold tolerance, in: Denlinger, D.L., Lee, R.E. (Eds.), Low Temperature Biology of Insects. Cambridge University Press, Cambridge, UK, pp. 3-34.

Lumley, L.M., Pouliot, E., Laroche, J., Boyle, B., Brunet, B.M.T., Levesque, R.C., Sperling, F.A.H., Cusson, M., 2020. Continent $\square$ wide population genomic structure and phylogeography of North America's most destructive conifer defoliator, the spruce budworm ( Choristoneura fumiferana ). Ecol. Evol. ece3.5950. https://doi.org/10.1002/ece3.5950

Marshall, K., Roe, A.D., n.d. Surviving in a frozen forest: the physiology of eastern spruce budworm overwintering. Physiology.

Marshall, K.E., Gotthard, K., Williams, C.M., 2020. Evolutionary impacts of winter climate change on insects. Curr. Opin. Insect Sci. 41, 54-62. https://doi.org/10.1016/j.cois.2020.06.003

Marshall, K.E., Sinclair, B.J., 2015. The relative importance of number, duration and intensity of cold stress events in determining survival and energetics of an overwintering insect. Funct. Ecol. 29, 357-366. https://doi.org/10.1111/1365-2435.12328

Marshall, K.E., Sinclair, B.J., 2012. The impacts of repeated cold exposure on insects. J. Exp. Biol. 215, 1607-1613. https://doi.org/10.1242/jeb.059956

Marshall, K.E., Sinclair, B.J., 2010. Repeated stress exposure results in a survival-reproduction trade-off in Drosophila melanogaster. Proc. R. Soc. B Biol. Sci. 277. https://doi.org/10.1098/rspb.2009.1807

McMorran, A., 1965. A Synthetic Diet for the Spruce Budworm, Choristoneura fumiferana. Can. Entomol. 97, 58-62. https://doi.org/10.4039/Ent9758-1

Mousseau, T.A., Fox, C.W., 1998. The adaptive significance of maternal effects. Trends Ecol. Evol. https://doi.org/10.1016/S0169-5347(98)01472-4

Nealis, V.G., 2016. Comparative ecology of conifer-feeding spruce budworms (Lepidoptera: Tortricidae). Can. Entomol. 148, S33-S57. https://doi.org/10.4039/tce.2015.15

Overgaard, J., Sørensen, J.G., Loeschcke, V., 2010. Genetic variability and evolution of cold-tolerance, in: Low Temperature Biology of Insects. Cambridge University Press, pp. 276-296. https://doi.org/10.1017/CBO9780511675997.012

Park, Y., Kim, Y., 2013. RNA interference of glycerol biosynthesis suppresses rapid cold hardening of the beet armyworm, Spodoptera exigua. J. Exp. Biol. 216, 4196-4203. 
Perrault, K., Wardlaw, A. A., Candau, J.-N., Irwin, C. L., Demidovich, M., MacQuarrie, C.J.K., Roe, A. D., 2021. From branch to bench: establishing wild spruce budworm populations into laboratory colonies for the exploration of local adaptation and plasticity. Can. Entomol. [online early]. https://doi.org/10.4039/tce.2021.1

Pigliucci, M., 2001. Phenotypic Plasticity: Beyond Nature and Nurture. JHU Press, Baltimore.

Qin, W., Doucet, D., Tyshenko, M.G., Walker, V.K., 2007. Transcription of antifreeze protein genes in Choristoneura fumiferana. Insect Mol. Biol. 16, 423-434. https://doi.org/10.1111/j.1365-2583.2007.00743.x

Rajamohan, A., Sinclair, B.J., 2009. Hardening trumps acclimation in improving cold tolerance of Drosophila melanogaster larvae. Physiol. Entomol. 34, 217-223. https://doi.org/10.1111/j.1365-3032.2009.00677.x

724

725

726

727

728

729

730

731

732

733

734

735

736

737

738

739

740

Régnière, J., 2009. Predicting insect continental distributions from species physiology. Unasylva 60, 37-42.

Régnière, J., 1990. Diapause termination and changes in thermal responses during postdiapause development in larvae of the spruce budworm, Choristoneura fumiferana. J. Insect Physiol. 36, 727-735. https://doi.org/10.1016/0022-1910(90)90046-I

Roberts, S.P., Feder, M.E., 1999. Natural hyperthermia and expression of the heat shock protein Hsp70 affect developmental abnormalities in Drosophila melanogaster. Oecologia 121, 323-329. https://doi.org/10.1007/s004420050935

Roe, A.D., Demidovich, M., Dedes, J., 2017. Origins and History of Laboratory Insect Stocks in a Multispecies Insect Production Facility, With the Proposal of Standardized Nomenclature and Designation of Formal Standard Names. J. Insect Sci. 18. https://doi.org/10.1093/JISESA/IEY037

Sanders, C.J., 1991. Biology of North American spruce budworm., in: van der Geest, L.P.S., Evenhuis, H.H. (Eds.), Tortricid Pests, Their Biology, Natural Enemies and Control. Elsevier Science, Amsterdam, The Netherlands, pp. 579-620.

Sinclair, B.J., 1999. Insect cold tolerance: How many kinds of frozen? Eur. J. Entomol. 96, 157-164.

Sinclair, B.J., Coello Alvarado, L.E., Ferguson, L. V., 2015. An invitation to measure insect cold tolerance: Methods, approaches, and workflow. J. Therm. Biol. 53, 180-197. https://doi.org/10.1016/j.jtherbio.2015.11.003

Sinclair, B.J., Williams, C.M., Terblanche, J.S., 2012. Variation in Thermal Performance among Insect Populations. Physiol. Biochem. Zool. 85, 594-606. https://doi.org/10.1086/665388

Strachan, L.A., Tarnowski-Garner, H.E., Marshall, K.E., Sinclair, B.J., 2011. The evolution of cold tolerance in Drosophila larvae. Physiol. Biochem. Zool. 84, 43-53. https://doi.org/10.1086/657147 
750

751

752

753

754

755

756

757

758

759

760

761

762

763

764

765

766

767

768

769

770

771

772

773

774

775

776

777

778

779

Sturtevant, B.R., Achtemeier, G.L., Charney, J.J., Anderson, D.P., Cooke, B.J., Townsend, P.A., 2013. Author', s personal copy Agricultural and Forest Meteorology Long-distance dispersal of spruce budworm ( Choristoneura fumiferana Clemens ) in Minnesota ( USA ) and Ontario ( Canada ) via the atmospheric pathway. Agric. For. Meteorol. 168, 186-200.

Sultan, S.E., Spencer, H.G., 2002. Metapopulation structure favors plasticity over local adaptation. Am. Nat. 160, 271-283. https://doi.org/10.1086/341015

Tauber, C.A., Tauber, M.J., 1986. Ecophysiological responses in life-history evolution: evidence for their importance in a geographically widespread insect species complex. Can. J. Zool. 64, 875-884. https://doi.org/10.1139/z86-131

Terblanche, J.S., Deere, J. a, Clusella-Trullas, S., Janion, C., Chown, S.L., 2007. Critical thermal limits depend on methodological context. Proc. Biol. Sci. 274, 2935-2942. https://doi.org/10.1098/rspb.2007.0985

Tyshenko, M.G., Doucet, D., Davies, P.L., Walker, V.K., 1997. The antifreeze potential of the spruce budworm thermal hysteresis protein. Nat. Biotechnol. 15, 887-890. https://doi.org/10.1038/nbt0997-887

Venables, W.N., Ripley, B.D., 2003. Modern Applied Statistics With S, 4th ed, Technometrics. Springer, New York. https://doi.org/10.1198/tech.2003.s33

Williams, C.M., Henry, H.A.L., Sinclair, B.J., 2015. Cold truths: How winter drives responses of terrestrial organisms to climate change. Biol. Rev. 90, 214-235. https://doi.org/10.1111/brv.12105

Woestmann, L., Saastamoinen, M., 2016. The importance of trans-generational effects in Lepidoptera. Curr. Zool. 62, 489-499. https://doi.org/10.1093/cz/zow029

Yampolsky, L.Y., Schaer, T.M.M., Ebert, D., 2013. Adaptive phenotypic plasticity and local adaptation for temperature tolerance in freshwater zooplankton. Proc. R. Soc. B Biol. Sci. 281. https://doi.org/10.1098/rspb.2013.2744

Zhang, X., Flato, G., Kirchmeier-Young, M., Vincent, L.A., Wan, H., Wang, X., Rong, R., Fyfe, J.C., L, G., Kharin, V. V., 2019. Changes in Temperature and Precipitation Across Canada. Canada's Chang. Clim. Rep. 112-193. 


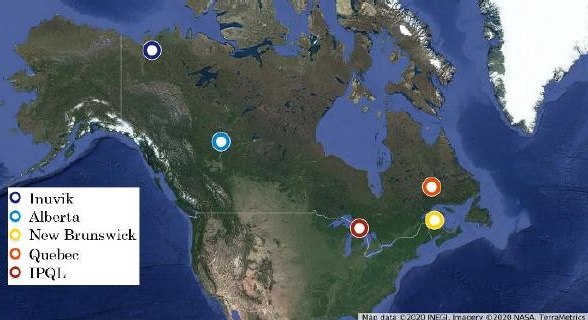


bioRxiv preprint doi: https://doi.org/10.1101/2021.04.02.438273; this version posted April 4, 2021. The copyright holder for this preprint (which was not certified by peer review) is the author/funder, who has granted bioRxiv a license to display the preprint in perpetuity. It is made

A)

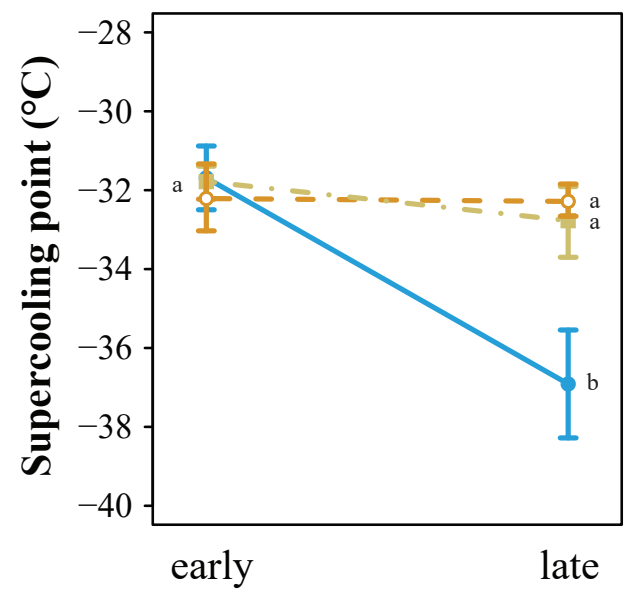

available under aCC-BY-ND 4.0 International license.

B)

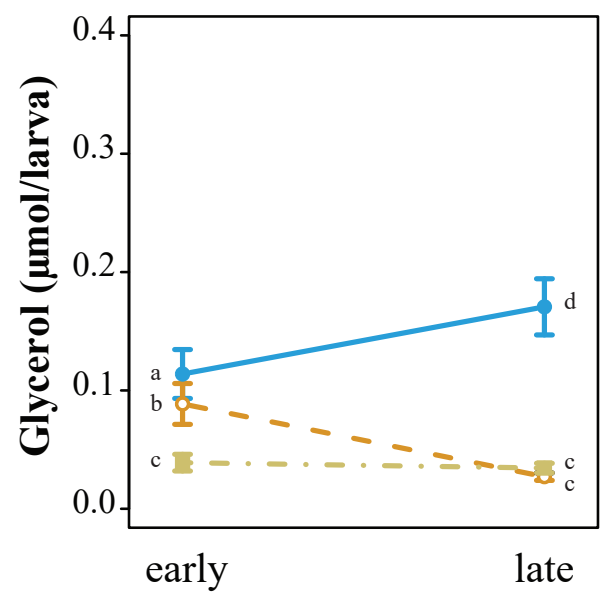

C)

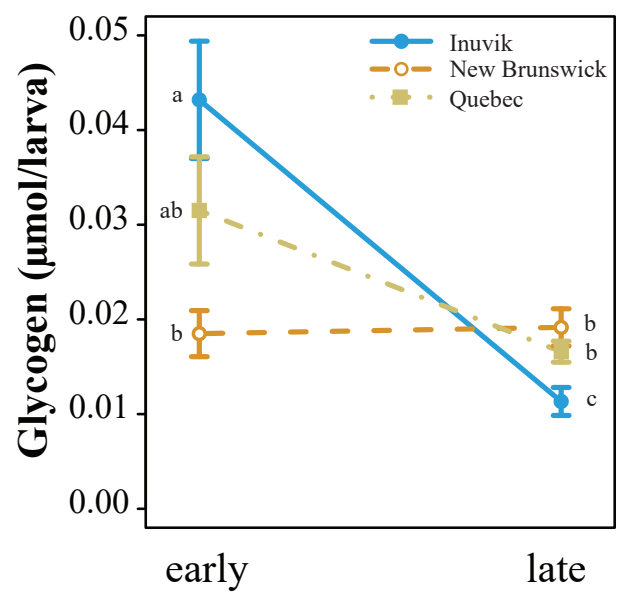

Time in diapause 
bioRxiv preprint doi: https://doi.org/10.1101/2021.04.02.438273; this version posted April 4, 2021. The copyright holder for this preprint (which A ) was not certified by peer review) is the authqrffonder, who has granted bioRxiv a license to display the preprint in perpetuity. It is made
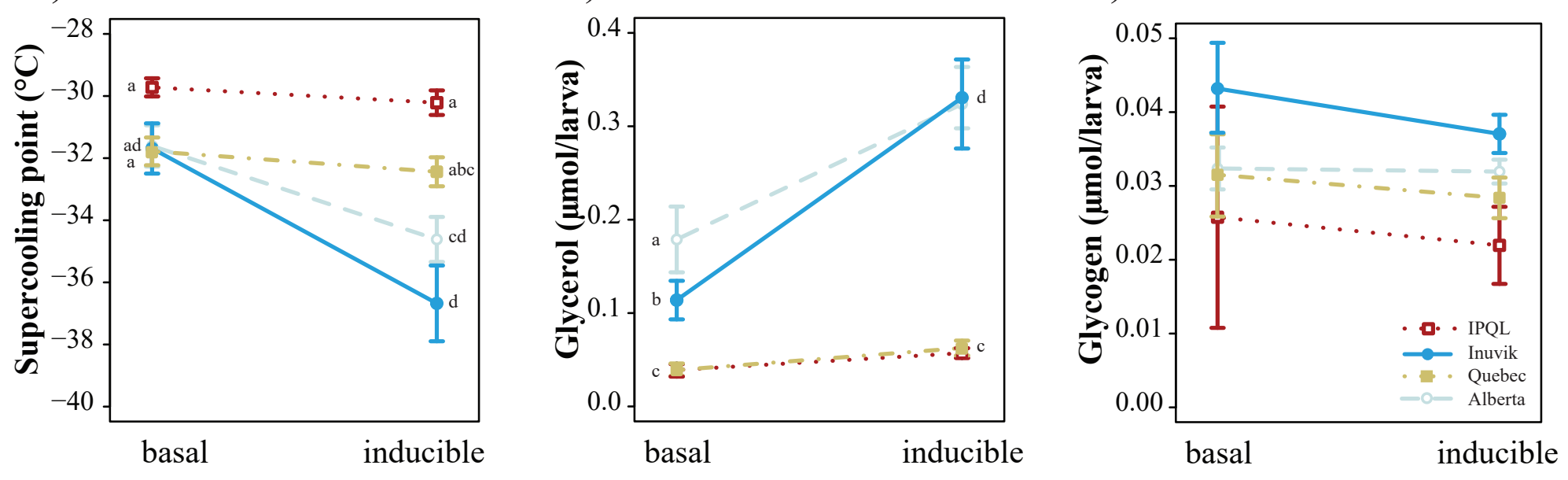

Treatment 
bioRxiv preprint doi: https://doi.org/10.1101/2021.04.02.438273; this version posted April 4, 2021. The copyright holder for this preprint (which was not certified by peer review) is the author/funder, who has granted bioRxiv a license to display the preprint in perpetuity. It is made available under aCC-BY-ND 4.0 International license.

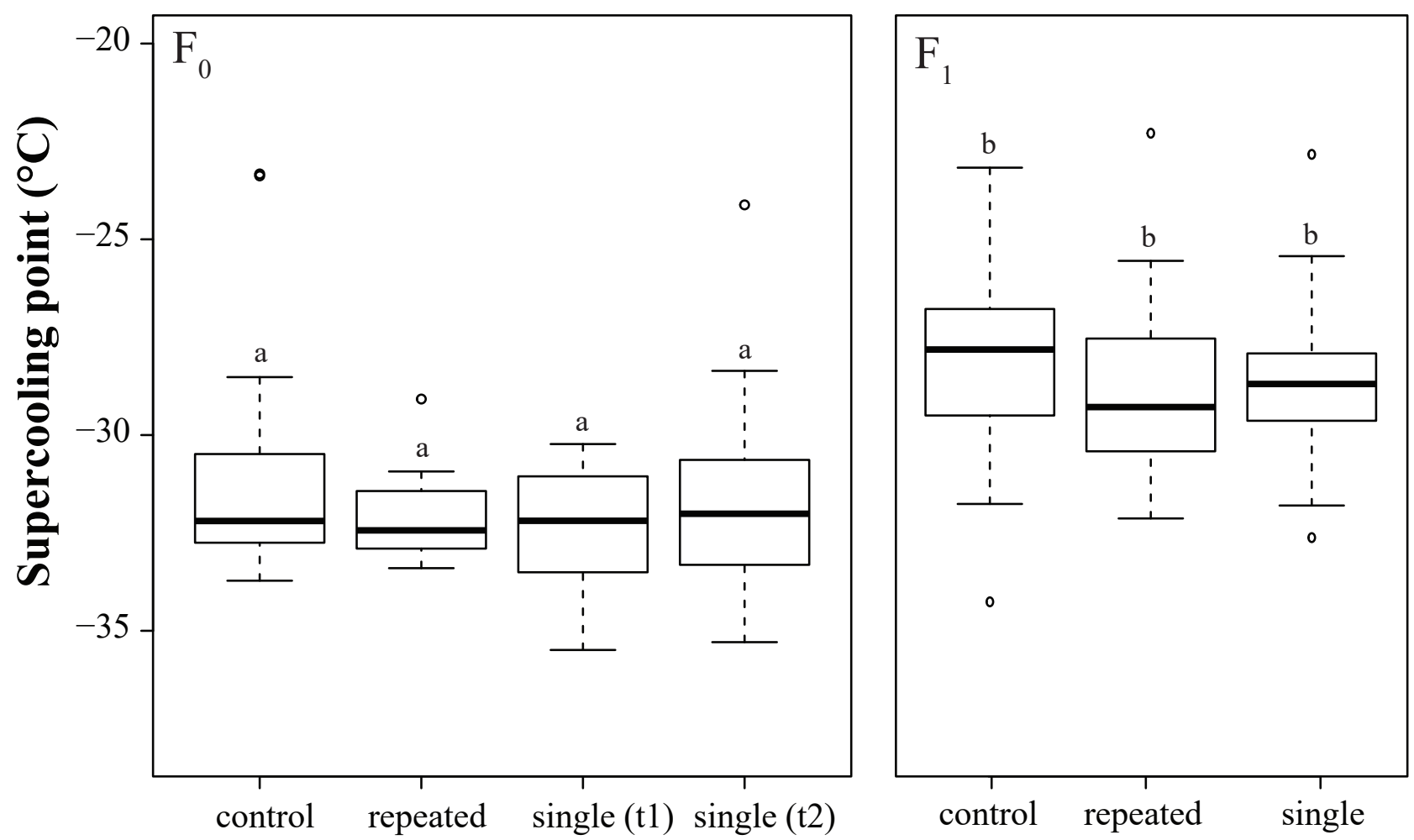

\section{Treatment}



was not certified by peer review) is the author/funder, who has granted bioRxiv a license to display the preprint in perpetuity. It is made
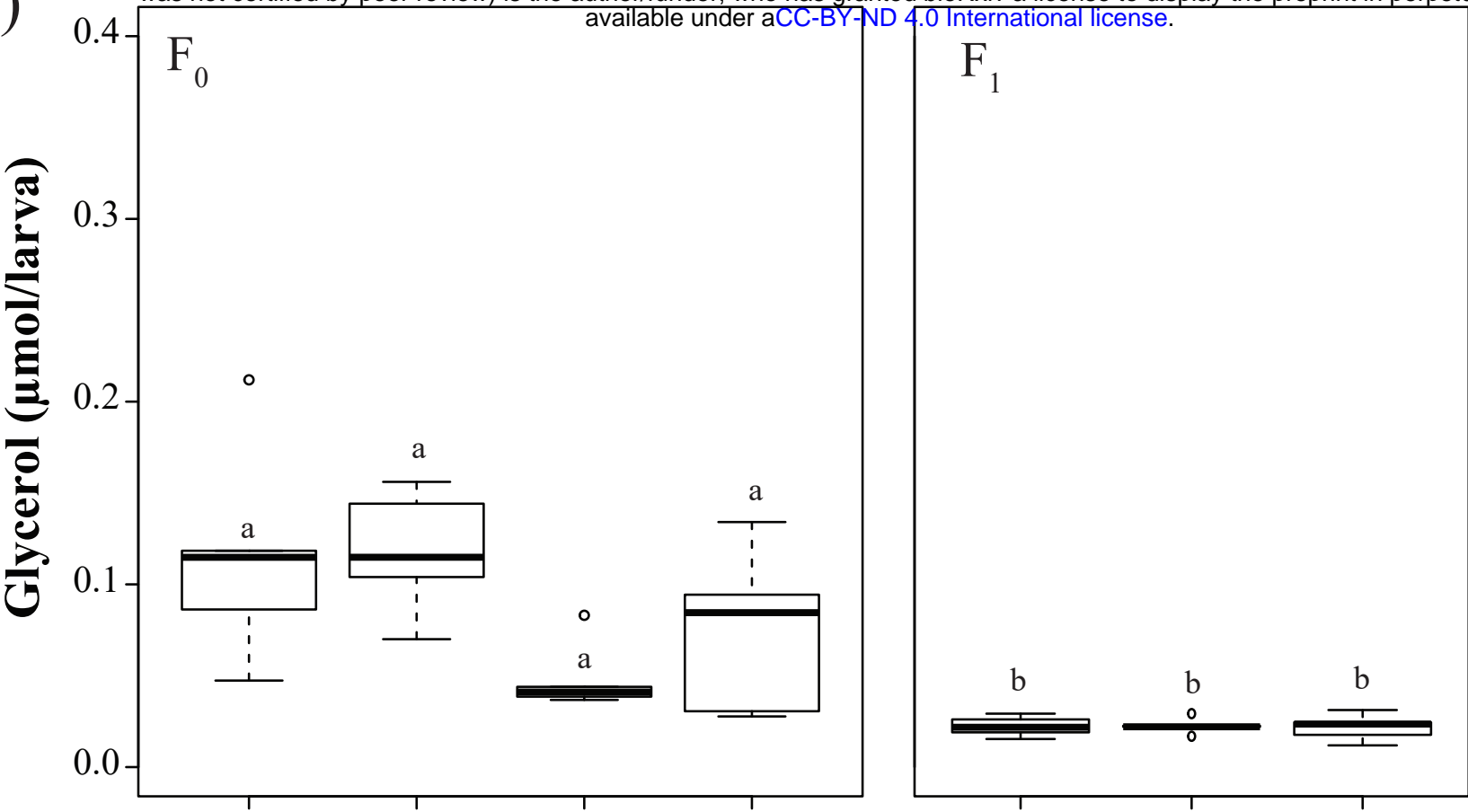

B)

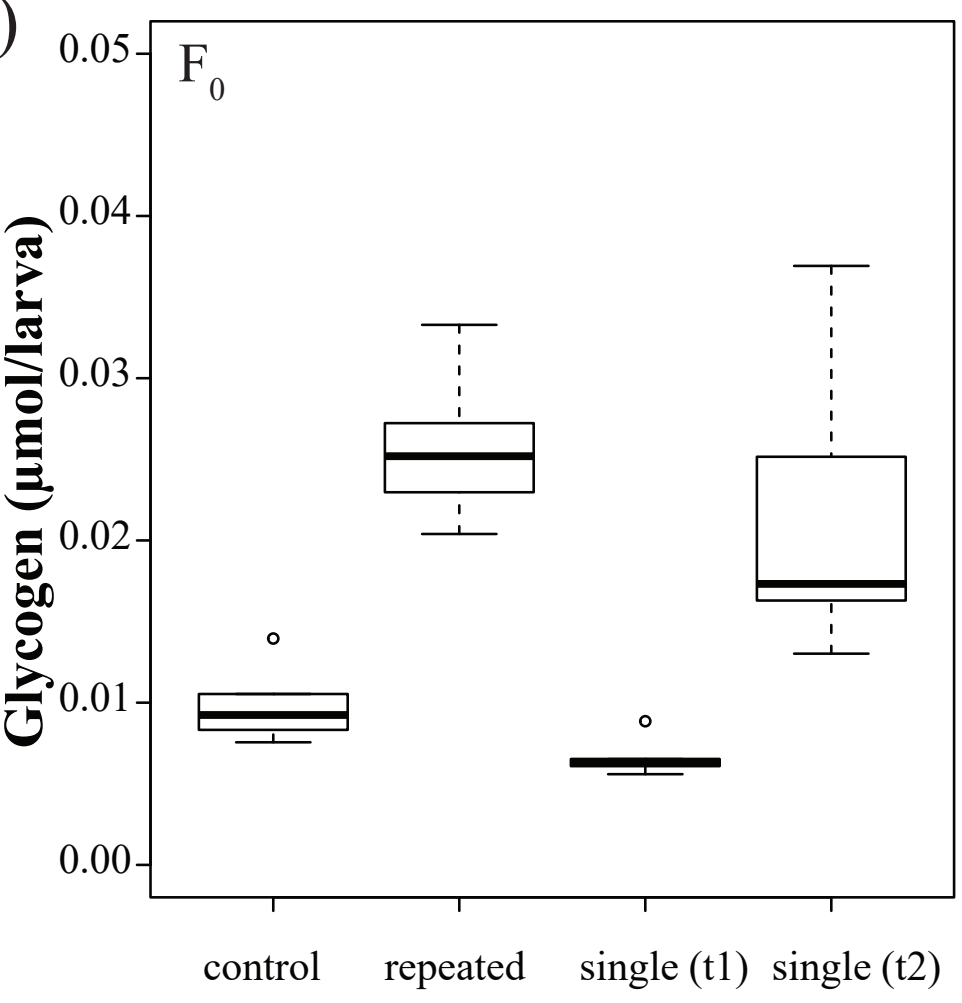

\section{$\mathrm{F}_{1}$}

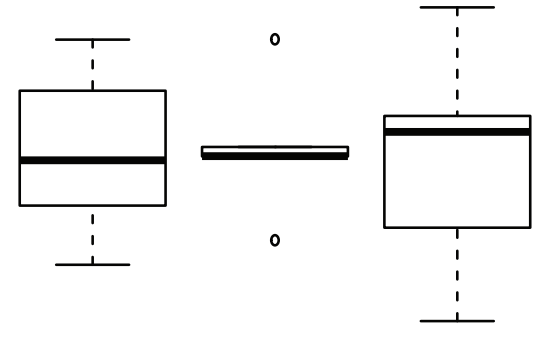

\section{Treatment}


